\title{
Research methods: Time to get excited!
}

Tiny Jaarsma, Anna Strömberg and David R. Thompson

The self-archived postprint version of this journal article is available at Linköping University Institutional Repository (DiVA):

http://urn.kb.se/resolve?urn=urn:nbn:se:liu:diva-164041

N.B.: When citing this work, cite the original publication.

Jaarsma, T., Strömberg, A., Thompson, D. R., (2020), Research methods: Time to get excited!, European Journal of Cardiovascular Nursing, 19(2), 96-97.

https://doi.org/10.1177/1474515120903973

Original publication available at:

https://doi.org/10.1177/1474515120903973

Copyright: SAGE Publications (UK and US)

http://www.uk.sagepub.com/home.nav 
Research Methods: Time to get excited!

Tiny Jaarsma, Anna Strömberg and David R. Thompson

Some of us love to think about research methods, some get quite heated about them, and some feel ambivalent about them and struggle through research sections of scientific papers or grant applications. Some readers of the European Journal of Cardiovascular Nursing have extensive formal research training, while others have informal training and learned by trial and error. Some of us never opened a research methods book after our training, while others may be constantly enrolling themselves in research webinars or on courses to stay updated with the newest insights. For all of us, there is good news: we now have a 'methods corner' in the Journal.

Science is constantly in transition and this has consequences for the methods that we apply and challenges we face in our research studies. The European Journal of Cardiovascular Nursing is dedicated to the advancement of knowledge in the field of cardiovascular care and the promotion of evidence-based clinical practice. This means that we publish articles with a diverse range of research methods, such as surveys ${ }^{1}$, qualitative studies ${ }^{2}$, pilot studies ${ }^{3}$, or randomized controlled trials ${ }^{4}$. These are just a few examples of the approaches needed to address the variety of research questions posed in cardiovascular clinical practice.

In the position statement on research in cardiovascular care that was published seven years ago by the Council on Cardiovascular Nursing and Allied Professionals (CCNAP), knowledge gaps in research related to cardiovascular patient care were identified, upcoming challenges explored and recommendations for future research given. ${ }^{5}$ With the recent transition of CCNAP to the Cardiovascular Nursing and Allied Professions (ACNAP) ${ }^{6}$ a discussion arose about the need for a new position statement about research in cardiovascular care. It was generally agreed that the main conclusions from the position statement still hold and the proposed research agenda remains relevant. However, while reviewing the position statement, our eye was caught by the statement that 'alternative trial designs can be considered' and 'a more sophisticated and balanced approach to appropriate research methods is needed'. Yet, when critically looking at our studies, researchers in cardiovascular care still tend to use traditional methods. In addition to the need to identify appropriate designs there are several issues that researchers in the area of cardiovascular patient care find challenging, such as how to deal with non-response and how to analyse data from patients and partners.

We believe, therefore, that it is timely to launch the 'Methods Corner' in the Journal. In the current issue you will find our second article in the 'Methods Corner'. Every issue of the European Journal of Cardiovascular Nursing will tackle a research issue that is relevant to our field. The editors of this series are Professor Philip Moons and Professor Christopher Lee, both experienced researchers and teachers. 
In the first issue of the Methods Corner Professor Moons explained how propensity weighting can be used in non-randomised studies. ${ }^{7}$

In the current issue Professor Lee gives an excellent introduction to dyad research, which is relevant for many of our researchers who collect data from patients and their caregivers.(add ref)

Maybe you as a reader have questions that have arisen during your research or maybe you have wondered about research methods that could also be of interest to others. You are welcome to send ideas for topics to present in the Methods Corner to the section editors

(Philip.Moons@kuleuven.be or leeddo@bc.edu).

More information about the Methods Corner you can be found in the section HeartBeat of the Journal (link here)

1. Fitzsimons D, Stepinska J, Kerins M, et al. Secondary prevention and cardiovascular care across Europe: A survey of European Society of Cardiology members' views. Eur J Cardiovasc Nurs. 2019:1474515119877999.

2. Olsson K, Naslund U, Nilsson J, Hornsten A. Hope and despair: patients' experiences of being ineligible for transcatheter aortic valve implantation. Eur J Cardiovasc Nurs. 2019;18(7):593600.

3. Bramwell SE, Meyerowitz-Katz G, Ferguson C, Jayaballa R, McLean M, Maberly G. The effect of an mHealth intervention for titration of insulin for type 2 diabetes: A pilot study. Eur J Cardiovasc Nurs. 2019:1474515119889764.

4. Chen $\mathrm{CH}$, Hung KS, Chung YC, Yeh ML. Mind-body interactive qigong improves physical and mental aspects of quality of life in inpatients with stroke: A randomized control study. Eur J Cardiovasc Nurs. 2019;18(8):658-666.

5. Jaarsma T, Deaton C, Fitzsimmons D, et al. Research in cardiovascular care: a position statement of the Council on Cardiovascular Nursing and Allied Professionals of the European Society of Cardiology. Eur J Cardiovasc Nurs. 2014;13(1):9-21.

6. Hansen TB, Neubeck L. Standing on the shoulders of giants: Reflecting on the history and creation of the new Association of Cardiovascular Nursing and Allied Professions. Eur J Cardiovasc Nurs. 2019;18(3):176-178.

7. Moons P. Propensity weighting: how to minimise comparative bias in non-randomised studies? Eur J Cardiovasc Nurs. 2020;19(1):83-88. 